\title{
Role of Rapid Onsite Evaluation (ROSE) of EUS-FNAC in Diagnostic Yield of Solid Mass Lesions
}

\author{
Manju Yadav ${ }^{*}$, Dilip Ramrakhiani², Ajay yadav³ ${ }^{3}$ Sandeep Nijhawan ${ }^{4}$ \\ ${ }^{1 *}$ Final Year Resident, ${ }^{2}$ Associate Professor, ${ }^{3}$ Professor \& Head, Department of Pathology, \\ ${ }^{4}$ Head, Department of Gastroentrology, S.M.S. Medical College \& Hospital, Jaipur, Rajasthan, India.
}

\begin{abstract}
Introduction: Endoscopic ultrasound guided fine needle aspiration cytology (EUS-FNA) is a preferred minimally invasive modality with low complication rates for cytological diagnosis of various gastrointestinal and mediastinal lesions. The present study was conducted to determine whether rapid on-site evaluation (ROSE) of cytology smears by cytopathologist improves the diagnostic yield of solid mass lesions on EUS-FNA.

Material and Methods: Total 112 patients from June 2014 through October 2015 referred for EUS-FNA of solid mass lesions were prospectively enrolled in this single center study out of which 56 were in group-I (without onsite cytopathologist) and 56 in group-II (with onsite cytopathologist). In group-I patients cytology slides were prepared by endoscopy nurse. In group-II patients cytology slides were prepared, stained and assessed for adequacy of sampling by onsite cytopathologist. The final cytopathological diagnosis (definitely positive, definitely negative or inadequate) was compared between the two groups.

Results: A total of 61 EUS-FNA procedures in group I and 59 in group II were performed. Abdominal lymph nodes were the most common target sites in both the groups. A significantly higher number of needle passes were performed without onsite
\end{abstract}

\section{INTRODUCTION}

Endoscopic ultrasound (EUS) was first introduced in early 1980s and was developed in an attempt to improve ultrasound imaging of the pancreas.Since its introduction Endoscopic ultrasound has evolved into an accepted and valuable endoscopic modality for diagnosis and management of many gastrointestinal disorders. ${ }^{1}$ Nowadays endoscopic ultrasound (EUS) has become a wellestablished modality in diagnosing and staging various gastrointestinal, pancreatico-biliary, and mediastinal lesions as well as staging of various malignancies. ${ }^{2-5}$ However, with a specificity of $75-82 \%$ EUS alone has limited ability to discriminate between malignant and benign lesions. In the early 1990s, EUSguided fine-needle aspiration (EUS-FNA) emerged as a minimally invasive technique to obtain cytological specimens from lesions within, or immediately adjacent to, the upper or lower gastrointestinal tract. In experienced hands, EUS-FNA has a proven accuracy of $95 \%$ with a diagnostic yield of $100 \%$ for the detection of various malignancies. ${ }^{6-10}$ A successful cytological diagnosis following EUS-FNA requires an experienced endosonographer, a specimen of adequate cellularity, a highquality cytology slide preparation and an on-site cytopathologist. ${ }^{11}$ Up to $32 \%$ of EUS- FNA specimens may be non-diagnostic due to scant cellularity or poor slide preparation causing "crush artifact" cytopathologist (3.59 vs 2.88; $\mathrm{P}=0.0001)$. The final cytopathological diagnosis was definite in $71.4 \%$ in group I compared with $87.5 \%$ in group II. ( $P=0.035)$ The percentage of inadequate diagnosis was $23.2 \%$, in group I and $8.9 \%$ in group II. $(P=0.035)$

Conclusion: ROSE by cytopathologist and interpretation significantly improves the diagnostic yield of EUS-FNA.

KEY WORDS: EUS, FNAC, ROSE.

*Correspondence to:

Dr Manju Yadav, Final year resident, Pathology, S.M.S. Medical College \& Hospital, Jaipur.

Email: manjubhushanyadav@gmail.com

Article History:

Received: 17-04-2016, Revised: 19-04-2016, Accepted: 29-05-2016

\begin{tabular}{|l|c|}
\hline \multicolumn{2}{|c|}{ Access this article online } \\
\hline Website: & Quick Response code \\
www.jimrp.com & \\
DOI: & \\
10.21276/ijmrp.2016.2.3.036 & \\
\hline
\end{tabular}

when performed by inexperienced personnel. ${ }^{12}$ Onsite interpretation of EUS-FNA specimens is beneficial for rapid clinical diagnosis and decision making and can improve the quality of direct smears by limiting the amount of crush and air drying artifact. ${ }^{13-15}$ The aim of this study was to determine whether rapid on-site evaluation (ROSE) of cytology smears by cytopathologist improves the diagnostic yield of solid mass lesions on EUS-FNA.

\section{MATERIALS AND METHODS}

Study design: This was a prospective, single center, comparative analytical type of study conducted in Department of Pathology and Gastroenterology, S. M. S. Medical College \& Hospital (a tertiary care center) Jaipur.

Study population: Consecutive patients referred for EUS-FNA of solid mass lesions were prospectively enrolled from June 2014 through October 2015 and divided in two groups, 56 were in group I (without onsite cytopathologist) and 56 in group || (with onsite cytopathologist). All patients provided written informed consent before undergoing the procedure.

Inclusion criteria included the following: Age >18years, presence of a solid mass lesion including mediastinal, pancreatic, retroperitoneal, peri-portal, G.I. tract, liver \& adrenal mass, confirmed by at least a single investigational modality such as 
computed tomography scan, magnetic resonance imaging or EUS, ability to provide written informed consent by patient and availability of an on-site cytopathologist.

Exclusion criteria included: hemodynamically unstable patients, Patients with coagulation abnormalities (INR >1.8) or thrombocytopenia (platelet count $<50,000$ ), patients with pure cystic lesions, inability to sample the lesion due to presence of intervening blood vessels and whether results of EUS-FNA would not impact on patient management. .

\section{EUS-FNA Examination Procedure}

During the study period, all procedures were performed in gastroenterology department by Gastroenterologists with varying experience (without any subspecialty training in Endoscopic ultrasound), using the Echoendoscope-Olympus linear EUS system (EU-ME1),(USA). EUS-FNA was performed using a 22gauge Wilson-Cook Echotip or Echotip ultra needle (Wilson-Cook, USA) either with or without suction. Procedures were performed in the endoscopy suite under moderate sedation with intravenous midazolam and intravenous meperidine. EUS aspirates were expelled from the needle either by blowing air through a $10-\mathrm{ml}$ syringe or by reinsertion of the stylet. A second procedure was completed in selected patients if the initial EUS-FNA was considered inconclusive for diagnosis. The smears were rendered adequate when the target organ had been adequately sampled for a reliable cytological diagnosis. Presences of any number of atypical cells in a low cellularity smear were also taken as an adequate smear. Mair point scoring system was used for lymph nodes and other organs to categorize the smears as inadequate or adequate for cytological diagnosis. A score of $>3$ was taken as diagnostically adequate. ${ }^{16}$

\section{Group I: Without Onsite Cytopathologist}

Group I included patients who had undergone EUS-FNA between June 2014 to December 2014. The number of needle passes and use of stylet for FNA was left at the discretion of the endosonographer and was determined by the degree of difficulty or when it appeared that adequate material had been obtained. The aspirated specimen was smeared onto cytology slides by the assisting endoscopy nurse. One-half of the prepared slides were fixed with an alcohol-based fixative and the other half were airdried. All slides were then sent to the pathology department for final cytopathological interpretation.

Group II: Onsite Cytopathologist

Group II included patients who had undergone EUS-FNA between January 2015 to October 2015. At the start of the procedure, the cytopathologist was notified so that she/ he could be in the endoscopy suite by the time the first needle needle pass was completed. The cytopathologist prepared all slides and stained them in the endoscopy suite with the Diff-Quik method. The stained specimen was then assessed microscopically for adequacy of tissue sampling and nature of disease (infectious, neoplastic) to determine the most immediate course of action including additional passes and a preliminary diagnosis or differential diagnosis was given. All specimens obtained and/or stained in the endoscopy suite were then taken by the cytopathologist to the pathology department for final cytopathological interpretation.

Calculation of diagnostic yield and Non-diagnostic rate: The diagnostic yield was calculated as the total number of specimens deemed to have adequate material to make a definite diagnosis out of the total number of specimens taken in the study expressed as a percentage. The non-diagnostic rate was the remaining cases considered to be insufficient for diagnosis out of the total number of specimens taken in the study expressed as a percentage.

Outcome Measures: Based on the pathologist's report, the final cytopathological diagnosis was categorized into these categories:

- Definitely positive and definitely negative for malignancy,

- Inconclusive diagnosis, i.e., cases interpreted as atypical or suspicious for malignancy.

- Inadequate diagnosis, i.e., cases with low number of cells or blood only (Mair score $<3$ ).

The primary outcome of this study was the difference in the number of definite (diagnostic yield) and inadequate (nondiagnostic rate) diagnostic categories between groups I and II. A secondary outcome was the difference in the number of needle passes undertaken and difference in number of repeat procedures advised in the two groups.

Statistical analysis: The data from the proforma was initially entered into the Microsoft Excel and then transferred to SPSS Version 14.0 for statistical analysis. Comparison of mean values between the two groups was done using Students unpaired " $\mathrm{t}$ " test, comparison of non-parametric data was done using Pearson's chi-square test and Odd's ratio was applied between definitive diagnosis and non-definitive diagnosis. Confidence interval was taken at $95 \%$. A P value of $<0.05$ was taken as statistically significant.

Table 1: Patient demographics and Procedure characterstics

\begin{tabular}{lccc}
\hline & $\begin{array}{c}\text { Group-l (without onsite } \\
\text { cytopathologist) }\end{array}$ & $\begin{array}{c}\text { Group-II (with onsite } \\
\text { cytopathologist) }\end{array}$ & P-Value \\
\hline Patients(n) & 56 & 56 & - \\
EUS-FNA procedures(n) & 61 & 59 & - \\
Male:Female & $2.1: 1$ & $2.1: 1$ & - \\
Mean age & 52.73 & 47.88 & - \\
Age range & $15-75$ & $18-79$ & - \\
Total no. of needle passes & 201 & 161 & 0.0001 \\
Avg. no. of needle passes & 3.59 & 2.88 & 0.0001 \\
Range of needle passes & $2-5$ & $2-4$ & - \\
Repeat procedures advised & 30.4 & 12.4 & 0.021 \\
\hline
\end{tabular}


Manju Yadav et al. EUS-FNAC in Diagnostic Yield of Solid Mass Lesions

Table 2: Diagnoses and rates of definitely positive and definitely negative endoscopic ultrasound-guided fine-needle aspiration cytology

\begin{tabular}{|c|c|c|c|c|c|}
\hline \multirow{2}{*}{\multicolumn{2}{|c|}{ Diagnosis }} & \multicolumn{2}{|c|}{$\begin{array}{l}\text { Group-I (without onsite } \\
\text { cytopathologist) }\end{array}$} & \multicolumn{2}{|c|}{$\begin{array}{l}\text { Group-II (with onsite } \\
\text { cytopathologist) }\end{array}$} \\
\hline & & No. & $\%$ & No. & $\%$ \\
\hline \multicolumn{2}{|c|}{ Definite positive for Malignancy } & 27 & 48.3 & 26 & 42.9 \\
\hline a) & Adrenal carcinoma & 1 & 1.8 & 0 & 0.0 \\
\hline b) & Esophageal carcinoma & 2 & 3.6 & 1 & 1.8 \\
\hline c) & Pancreatic carcinoma & 7 & 12.5 & 8 & 14.3 \\
\hline d) & Gallbladder carcinoma & 0 & 0.0 & 2 & 3.6 \\
\hline e) & $\mathrm{HCC}$ & 2 & 3.6 & 0 & 0.0 \\
\hline f) & Lymphoma & 0 & 0.0 & 4 & 7.1 \\
\hline g) & Lung carcinoma & 2 & 3.6 & 1 & 1.8 \\
\hline h) & Metastatic carcinoma & 11 & 19.6 & 6 & 10.7 \\
\hline i) & Metastatic malignant melanoma & 1 & 1.8 & 0 & 0.0 \\
\hline j) & Neuro-endocrine carcinoma & 0 & 0.0 & 1 & 1.8 \\
\hline k) & Gastric carcinoma & 1 & 1.8 & 1 & 1.8 \\
\hline \multicolumn{2}{|c|}{ Definite Negative for Malignancy } & 13 & 23.2 & 25 & 44.7 \\
\hline a) & Granulomatous lesion & 6 & 10.7 & 9 & 16.1 \\
\hline b) & Adrenocortical adenoma & 1 & 1.8 & 0 & 0.0 \\
\hline c) & Pancreatic pseudocyst & 1 & 1.8 & 0 & 0.0 \\
\hline d) & Pancreatic TB & 1 & 1.8 & 1 & 1.8 \\
\hline e) & $\mathrm{RH}$ & 4 & 7.1 & 15 & 26.8 \\
\hline \multirow{2}{*}{\multicolumn{2}{|c|}{$\begin{array}{l}\text { Inconclusive (Suspicious of malignancy) } \\
\text { Diagnosis }\end{array}$}} & 3 & 5.4 & 2 & 3.6 \\
\hline & & & & & \\
\hline \multicolumn{2}{|c|}{ Inadequate Diagnosis } & 13 & 23.2 & 5 & 8.9 \\
\hline \multicolumn{2}{|c|}{ Total } & 56 & $100 \%$ & 56 & $100 \%$ \\
\hline
\end{tabular}

Table 3: Cytopathological diagnosis

\begin{tabular}{|c|c|c|c|c|c|}
\hline Diagnosis & \multicolumn{2}{|c|}{$\begin{array}{l}\text { Group-I (without onsite } \\
\text { cytopathologist) }\end{array}$} & \multicolumn{2}{|c|}{$\begin{array}{l}\text { Group-II (with onsite } \\
\text { cytopathologist) }\end{array}$} & \multirow{2}{*}{$\begin{array}{l}\text { P- Value } \\
0.035 \text { (S) }\end{array}$} \\
\hline Definitive Diagnosis & 40 & 71.4 & 49 & 87.5 & \\
\hline Inadequate Diagnosis & 16 & 28.6 & 7 & 12.5 & $0.035(\mathrm{~S})$ \\
\hline Total & 56 & 100.0 & 56 & 100.0 & \\
\hline
\end{tabular}

Fig 1: Showing distribution of target FNAC site

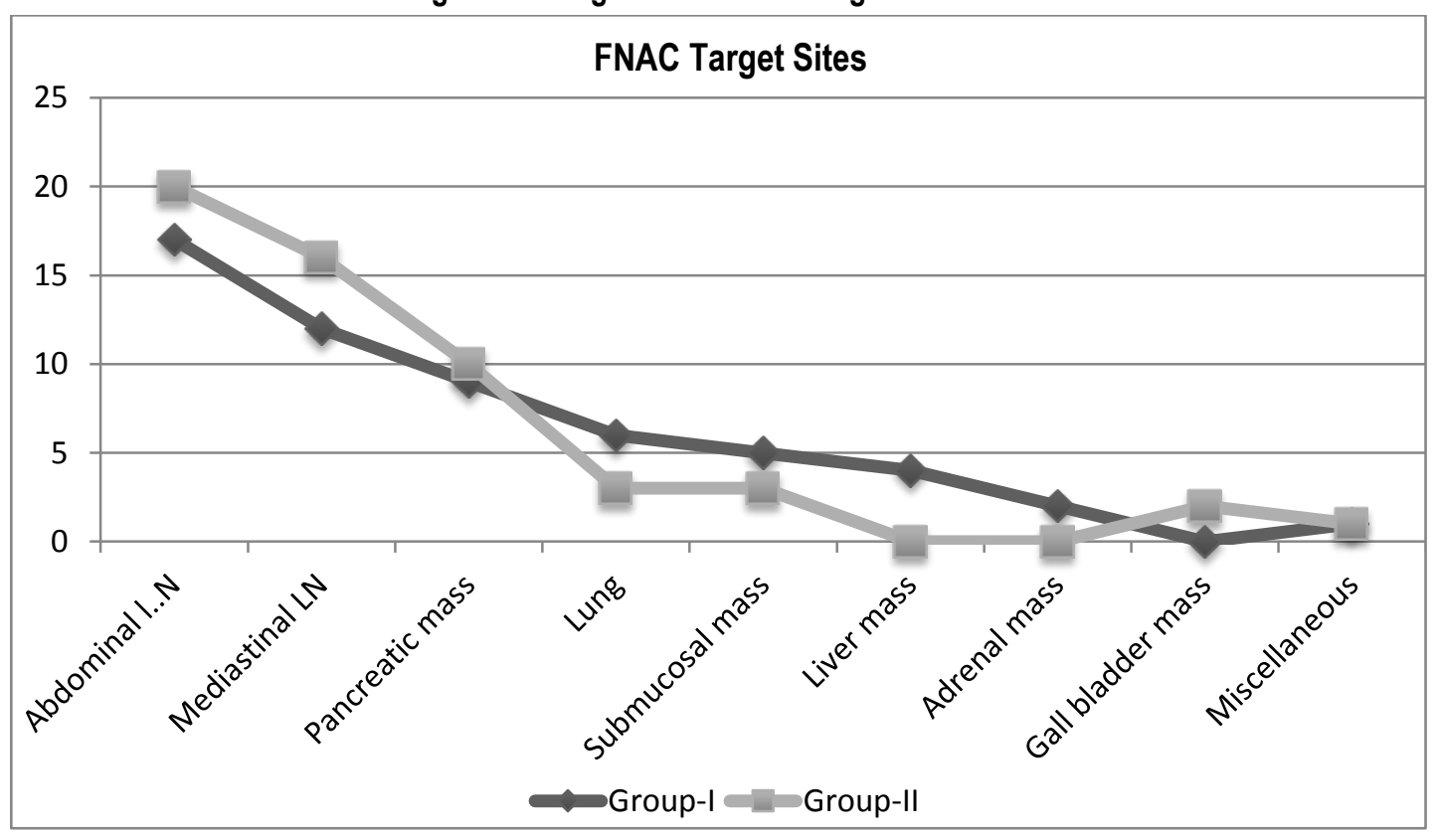




\section{RESULTS}

The patient demographics and procedure characteristics for groups I and II given in Table-1 and distribution of EUS-FNA target sites are shown in Figure-1. In both the groups sex distribution was equal with males $(67.9 \%)$ were predominantly affected. Male to female ratio was 2.1:1. The patients in group I were slightly older than group II with mean age of 52.73 years (range 15-75 years) in group I versus the mean age of 47.8 years (range18-75 years) for group II respectively. Maximum numbers of patients were of 41-60 years age group in both groups.

Abdominal lymph nodes were the most common target sites in both the groups( $30.4 \%$ in group I versus $35.7 \%$ in group II). This was followed by mediastinal lymph node and pancreatic mass (21.4\% and 16.15 in group I versus $28.6 \%$ and $17.9 \%$ in group II respectively). A total of 61 EUS-FNA procedures were performed in 56 patients in group I whereas 59 EUS-FNA procedures were performed in 56 patients in group II. Total number of needle passes in group I were 201 (mean 3.59 per patient; range 2 to 5 needle passes) versus 161 in group II(mean 2.88 per patient; range 2 to 4 needle passes). A significantly higher number of needle passes were performed in group I when on site cytopathologist was not available $(P<0.0001)$.

Repeat procedures were advised in $30.4 \%$ of cases in group I and $12.5 \%$ of cases in group II. The use of ROSE by an onsite cytopathologist significantly decreased the number of repeat procedures by approximately $41 \%$ ( $P$ value $=0.021$ )

Adequate specimens were obtained in $76.8 \%$ of patients in group I compared with $91.1 \%$ in group II. The presence of an onsite cytopathologist (group II) was associated with significantly higher number of adequate specimens. $(p=0.039)$

The final cytopathological diagnosis (Table No.-2,3) was reported as definite (definitely positive or definitely negative ) in 40 cases $(71.4 \%$ ) out of 56 EUS-FNA cases in group I compared with 49 cases $(87.5 \%)$ out of 59 cases in group II. . (P value $=0.035$; $95 \% \mathrm{Cl}$ of difference: 0.1338 to 0.9530 .) Three $(5.4 \%)$ patients in group I and two (3.6\%) patients in group II were diagnosed as inconclusive (suspicious of malignancy). Inadequate diagnosis was reported in $13(23.2 \%)$ patients in group I and $5(8.9 \%)$ patients in group II. $(\mathrm{P}=0.035)$

\section{DISCUSSION}

EUS-FNA is an accurate, safe and cost-effective technique to obtain tissue samples for the diagnosis and staging of various luminal and non-luminal gastrointestinal lesions as well as staging of various malignancies such as lung cancer. ${ }^{2-5}$

The role of ROSE has been mainly studied in percutaneous FNA. In this context, ROSE of FNA specimens by a cytopathologist is beneficial for rapid clinical diagnosis and decision making. Published data suggest that the presence of a cytopathologist in the endoscopy suite during EUS-FNA is useful and cost-effective by reducing the number of unsatisfactory samples and repeat procedures. ${ }^{17-21}$

In our study we have demonstrated that onsite processing and interpretation of cytological specimens by a cytopathologist had a significant impact on the diagnostic yield of EUS-FNA. The diagnostic yield was increased from $71.4 \%$ to $87.5 \%$ with ROSE by cytopathologist $(O R=0.35 ; P=0.035)$. In our study the proportion of patients with an unsatisfactory specimens was only
$8.9 \% \%$ with an onsite cytopathologist compared with $23.2 \% \%$ without cytopathologist $(\mathrm{OR}=0.32 \mathrm{P}=0.046)$. The influence of an onsite cytopathologist has been shown in numerous other studies to improve the diagnostic yield of EUS-FNA specimens and to reduce the rate of unsatisfactory samples obtained through this method.

Klapman et al. ${ }^{15}$ compared the EUS-FNA cytology results obtained by same endosongraphers at two centers, one with ROSE and one without ROSE and demonstrated that the presence of an onsite cytopathologist improved the diagnostic yield of EUS-FNA. A definitive positive or negative diagnosis for malignancy was given in $78 \%$ cases in patients with onsite cytopathologist compared with $52 \%$ without a cytopathologist $(\mathrm{OR}=2.94 ; \mathrm{P}=0.001)$ and the rate of patients with an unsatisfactory sample was $9 \%$ when on site cytopathologist was present, and $20 \%$ in absence of cytopathologist. $(\mathrm{OR}=0.36 ; \mathrm{P}=$ $0.035)$

In study by Ecka et al.22 the author's demonstrated that ROSE by cytopathologist is associated with higher diagnostic yield $(97.7 \%$ vs. $64.8 \%, P=0.001$ ) and lower number of inadequate specimens (29.6\% vs.2.21\%, $P=0.001)$.

Alsohaibani et $a^{23}$ demonstrated that the diagnostic yield increased from $53 \%$ to $77 \% \%$ in presence of onsite cytopathologist. $(\mathrm{P}=0.01)$.

Iglesias et al. ${ }^{24}$ in a study of 182 patients showed that presence of onsite cytopathologist was associated with lower number of unsatisfactory samples (1.0 vs.12.6\%, $\mathrm{P}=0.002)$ and higher diagnostic yield for malignancy ( $96.8 \%$ vs $78.2 \%, P=0.002$ ).

Collin et al. ${ }^{25}$ also showed a higher diagnostic yield ( $67 \%$ vs. $27 \%$ ) in presence of onsite cytopathologist. $(P<0.001)$ Similar findings had been shown by Eloubeidi et al. ${ }^{6}$ and Nasuti et al. ${ }^{11}$ and Silverman et al. ${ }^{26}$

Schmidt et al. ${ }^{27}$ in a review showed a considerable variability across studies with an average of $12 \%$ improvement with ROSE and $65 \%$ of the variability in the adequacy rate with ROSE was found to occur because of differences in the adequacy rate without ROSE. The presence of an onsite cytopathologist also minimizes the incidence of crush and air-drying artifacts seen with slides prepared by inexperienced personnel, and ensures adequacy of sample cellularity.

In study by Mehmood et al. ${ }^{28} 93.9 \%$ patients with ROSE had an adequate specimens for diagnosis. Matynia et al..$^{29}$ demonstrated that ROSE was associated with upto $3.5 \%$ improvement in adequacy rates for EUS-FNA of solid pancreatic lesions.

In our study, average number of needle passes in group with onsite cytopathologist, were 2.88 per patient (range 2 to 4 ) while in group without onsite cytopathologist were 3.59 per patient (range 2 to 5). A significantly higher number of needle passes were undertaken when on site cytopathologist was not available ( $3.59 \pm 0.62$ vs $2.88 \pm 0.57 ; P=0.0001)$ which corresponds to the study of Iglesias-Garcia et al. ${ }^{24}$ which demonstrated that a significantly higher number of needle passes were performed without ROSE $(3.5 \pm 1.0$ vs $2.0 \pm 0.7 ; P<0.001))$.

Erickson et al. ${ }^{30}$ also showed that without onsite cytopathologist a greater number of needle passes would be required for diagnosing pancreatic masses.

In our study, the increased diagnostic yield led to reduction in the number of repeat procedures from $30.4 \%$ to $12.5 \%$. The use of 
ROSE significantly decreased the number of repeated procedures by approximately $41 \%(P=0.021)$.

Collin et al. ${ }^{25}$ showed that the percentage of repeat procedures on the non-ROSE group was $5.8 \%$, which was slightly higher than in the ROSE group (2.9\%). The number of repeated procedures was decreased by approximately $50 \%$ by onsite cytopathologist $(P=$ 0.024). Nasuti et al. ${ }^{11}$ and other investigators ${ }^{12,21}$ also reported a cost benefit by reducing the number of repeat FNAC procedures for non-diagnostic specimens in the ROSE group.

In our study although a cost analysis was not performed, one can speculate this approach to be cost saving by preventing repeat procedures.

However few recent studies do indicate that onsite evaluation offers no benefit. Nguyen et al. ${ }^{31}$ reported fair agreement between cytotechnologists and EUS-technologists with regards to final cytopathological assessment of adequacy.

Cermark et al. ${ }^{32}$ also showed in their study that onsite evaluation offers no benefit in reducing the non-diagnostic rate. Similar reports were also observed by Schmidt et al. ${ }^{33}$, Perri et al. ${ }^{34}$ and Kim et al. ${ }^{35}$ and Nayar et al. ${ }^{36}$

In some studies it was shown that ROSE only decreases the number of needle passes to achieve a desired adequacy rate. ${ }^{37}$ Schmidt et al. ${ }^{38}$ reported that ROSE of EUS-FNA specimens was associated with an improvement in adequacy rates at sites with low adequacy rate without ROSE . $(<90 \%)$ ROSE has no impact on diagnostic yield.

In a study by Kate O'Conner et al. ${ }^{39}$ the overall accuracy, diagnostic yield and non-diagnostic rate did not significantly differ from those of studies that did have onsite evaluation.

There are, however some limitations in design of our study. The study was single center prospective review and included a limited number of patients. All procedures were performed by gastroenterologists with varying experience and none of them had subspecialty training in Endoscopic ultrasound and not all samples were handled and prepared by same endoscopy nurse. Most of the studies in the literature are based on pancreatic EUS-FNA studies but in our study pancreatic EUS-FNA comprised only 16$18 \%$ of cases. All these limitations can explain part of the discrepant results obtained in our studies and other studies.

\section{CONCLUSION}

Our study shows that ROSE by cytopathologists during EUS-FNA has a significant clinical impact by increasing the diagnostic yield of EUS-FNA in solid mass lesions. ROSE improves the adequacy rates of EUS-guided FNA specimens. In this context, ROSE appears to be a useful tool for optimizing the yield of the procedure.

The use of ROSE decreased the number of repeated procedures by approximately $41 \%$.Although a cost analysis was not performed as part of this study; one can speculate this approach to be cost-saving by preventing repeat procedures.

We therefore recommend to allocate a cytopathologist for onsite interpretation for adequacy of tissue sampling in centers where the services of a cytopathologist are not available.

However the diagnostic performance depends upon the presence of a skilled team, including both endosonographers and cytopathologists. So a close interaction between an endoscopist and a cytopathologist for improving the diagnosis of various lesion is recommended.

\section{ACKNOWLEDGEMENTS}

The authors acknowledge Dr. Kanwalpreet Kaur for her assistance with the statistical analysis.

\section{REFERENCES}

1. DiMagno EP, Buxton JL, Regan PT, Hattery RR, Wilson DA, Suarez JR, Green PS. Ultrasonic endoscope. Lancet 1980; I:629-31. 2. Boyce GA, Sivak MV, Jr, Lavery, et al. Endoscopic ultrasound in the pre-operative staging of rectal carcinoma. GastrointestEndosc 1992; 38:468-471.

3. Heintz A, Mildenberger $P$, Georg M, Braunstein S, Junginger T. Endoscopic ultrasonography in the diagnosis of regional lymph nodes in esophageal and gastric cancer-Results of studies in vitro. Endoscopy 1993;25:231-235.

4. Srinivasan R, Bhutani MS, Thosani N, et al. Clinical impact of EUSFNA of mediastinal lymph nodes in patients with known or suspected lung cancer or mediastinal lymph nodes of unknown etiology. J Gastrointestin Liver Dis 2012; 21:145-152.

5. Eloubeidi MA. Endoscopic ultrasound-guided fine-needle aspiration in the staging and diagnosis of patients with lung cancer. Semin.Thorac.Cardiovasc.Surg. 2007;19:206-211.

6. Eloubeidi MA, Jhala D, Chhieng DC, et al. Yield of endoscopicultrasound-guided fine-needle aspiration biopsy in patients with suspected pancreatic carcinoma. Cancer 2003; 99:285-292.

7. Chang KJ, Katz KD, Durbin TE, et al. Endoscopic ultrasound guided fine-needle aspiration. Gastrointest Endosc 1994; 40:694-699. 8. Chhieng DC, Jhala D, Jhala N, et al. Endoscopic ultrasoundguidedfine-needle aspiration biopsy: A study of 103 cases. Cancer 2002; 96:232-239.

9. Gress FG, Hawes RH, Savides TJ, Ikenberry SO, Lehman GA. Endoscopic ultrasound-guided fine-needle aspiration biopsy using linear array and radial scanning endosonography.Gastrointest.Endosc 1997;45:243-250.

10. Bentz JS, Kochman ML, Faigel DO, Ginsberg GG, Smith DB,Gupta PK. Endoscopic ultrasound-guided real-time fine-needle aspiration: Clinicopathologic features of 60 patients. DiagnCytopathol 1998; 18:98-109.

11. Nasuti JF, Gupta PK, Baloch ZW. Diagnostic value and cost effectiveness of on-site evaluation of fine-needle aspiration specimens: Review of 5,688 cases. DiagnCytopathol 2002; 27:1-4.

12. PelliseUrquiza $M$, Fernandez-Esparrach $G$, Sole $M$, et al. Endoscopic ultrasound-guided fine needle aspiration: predictive factors of accurate diagnosis and cost-minimization analysis of on-site pathologist. GastroenterolHepatol 2007; 30:319-324.

13. Diacon AH, Schuurmans MM, Theron J, et al. Utility of rapid onsite evaluation of transbronchial needle aspirates. Respiration 2005; 72:182-188.

14. Tournoy KG, Praet MM, van Maele G, van Meerbeeck JP. Esophageal endoscopic ultrasound with fine-needle aspiration with an onsite cytopathologist: High accuracy for the diagnosis of mediastinal lymphadenopathy. Chest 2005; 128:3004-3009.

15. Klapman JB, Logrono R, Dye CE, Waxman I. Clinical impact of onsite cytopathology interpretation on endoscopic ultrasound guided fine needle aspiration. Am J Gastroenterol 2003; 98:1289-1294.

16. Bharathi K, Anuradha S, Khalique A, Venkatesh S. A prospective study to compare the aspiration and non-aspiration techniques in fine needle cytology of lymph node and to evaluate the diagnostic accuracy of aspiration cytology in lymph node lumps. Int J Biol Med Res. 2012; 3:2147-2152.

17. Kocjan G, Chandra A, Cross P, Denton K, Giles T, Herbert A, Smith P, Remedios D, Wilson P. BSCC Code of Practice-fine needle aspiration cytology. Cytopathology 2009; 20: 283-296. 
18. Nasuti JF, Gupta PK, Baloch ZW. Diagnostic value and costeffectiveness of on-site evaluation of fine-needle aspiration specimens: review of 5,688 cases. Diagn Cytopathol 2002; 27:1-4

19. Woon C, Bardales RH, Stanley MW, Stelow EB. Rapid assessment of fine needle aspiration and the final diagnosis-how often and why the diagnoses are changed. Cytojournal.2006; 3: 25

20. Hayashi $\mathrm{T}$, Ishiwatari $\mathrm{H}$, Yoshida M, et al. Rapid on-site evaluation by endosonographer during endosonographic ultrasound-guided fine needle aspiration for pancreatic solid masses. J Gastroenterol Hepatol 2013; 28:656-663.

21. Layfield LJ, Bentz JS, Gopez EV. Immediate on-site interpretation of fine-needle aspiration smears: A cost and compensation analysis. Cancer 2001; 93:319-322.

22. Ecka RS, Sharma M. Rapid On-Site Evaluation of EUS-FNA by Cytopathologist: An Experience of a Tertiary Hospital. Diagn. Cytopathol. 2013;41:1075-1080.

23. Alsohaibani F. Does onsite cytotechnology evaluation improve the accuracy of endoscopic ultrasound-guided fine-needle aspirationbiopsy? Cancer J Gastroenterol 2009; 23:26-30.

24. Iglesias GJ, Dominguez-Munoz JE, Abdulkader I, et al. Influence of on-site cytopathology evaluation on the diagnostic accuracy of endoscopic ultrasound-guided fine needle aspiration (EUS-FNA) of solid pancreatic masses. Am J Gastroenterol 2011; 106:1705-1710. 25. Collins BT, Murad FM, Wang JF, Bernadt CT. Rapid on-site evaluation for endoscopic ultrasound-guided fine-needle biopsy of the pancreas decreases the incidence of repeat biopsy procedures. Cancer Cytopathol 2013; 121: 518-524.

26. Silverman JF, Finley JL, O'Brien KF, et al. Diagnostic accuracy and role of sites. ActaCytol 1989; 33:791-796.

27. Schimdt RL, Witt BL, Lopez-Calderon LE, Layfield LJ. The influence of rapid onsite evaluation on the adequacy rate of fine needle aspiration cytology: A systemic review and meta-analysis. Am J Clin Pathol 2013; 139:300-308.

28. Shafqat Mehmood, Amna Jahan, Asif Loya and Muhammed Aasim Yusuf.Onsite Cytopathology Evaluation and Ancillary Studies Benificial in EUS-FNA of Pancreatic, Mediastinal, Intra-abdominal, and Submucosal Lesions.Diagn. Cytopathol.2015; 43:278-286.

29. Anna P. Matynia , Robert L Schimdt, Gonzalo Barraza, Lester J Layfield, Ali A Siddiqui and Douglas G Adler. Impact of rapid on site evaluation on the adequacy of endoscopic-ultrasound guided fineneedle aspiration of solid pancreatic lesions: Asystemic review and meta-analysis. Journal of Gastroentrology and Hepatology.2014; 29: 697-705.

30. Erickson RA, Sayage-Rabie L, Avots-Avotins A. Clinical utility of endoscopic ultrasound guided fine needle aspiration. Acta Cytol 1997; 41:1647-1653
31. Nguyen YP, Maple JT, Zhang Q, et al: Reliability of gross visual assessment of specimen adequacy during EUS-guided FNA of pancreatic masses. Gastrointest Endosc 2009; 69: 1264-1270.

32. Cermak TS, Wang B, DeBrito P, Carroll J, Haddad N, Sidawy MK. Does on-site adequacy evaluation reduce the nondiagnostic rate in endoscopic ultrasound-guided fine-needle aspiration of pancreatic lesions? Cancer Cytopathol. 2012; 120:319-325

33. Schmidt RL, Adler DG. EUS-guided fine-needle aspiration of solid masses with or without on-site cytological evaluation: No paradox. Am J Gastroenterol 2012; 107:1446-1447

34. Perri F. EUS-guided FNA of solid pancreatic masses with or without on-site cytological evaluation: More sample adequacy with less needle passes? Am J Gastroenterol 2012; 107:490.

35. Kim J, Ryu JK, Park JM, et al: Clinical factors associated with accuracy of EUS-FNA for pancreatic or peripancreatic solid mass without on-site cytopathologists. J Gastroenterol Hepatol 2014; 29: 887-892.

36. Nayar MK, Chatterjee S, Wadehra V, Cunningham J, Leeds J, Oppong K. Does on site adequacy assessment by cytotechnologists improve results of EUS guided FNA of solid pancreaticobiliary lesions? JOP 2013; 14:44-49.

37. Schimdt RL, Kordy MA, Howard K, Layfield LJ, Hall BJ, Adler DG. Risk-benefit analysis of sampling methods for fine needle aspiration cytology: A mathematical modeling approach. Am J ClinPathol 2013; 139:336-344

38. Schimdt RL, Witt BL, Matynia AP, Barraza G, Layfield LJ, Adler DG. Rapid on-site evaluation increases endoscopic ultrasound guided fine needle aspiration adequacy for pancreatic lesions. Dig Dis Sci 2013; 58:872-882.

39. Kate O'Conner, Danny G.C, Hector H.L, Steven EK, John G, Michael FB, Alan AW, Fergal D, David FS. Acta Cytologica 2015; 59:305-310.

Source of Support: Nil. Conflict of Interest: None Declared.

Copyright: (c) the author(s) and publisher. IJMRP is an official publication of Ibn Sina Academy of Medieval Medicine \& Sciences, registered in 2001 under Indian Trusts Act, 1882.

This is an open access article distributed under the terms of the Creative Commons Attribution Non-commercial License, which permits unrestricted non-commercial use, distribution, and reproduction in any medium, provided the original work is properly cited.

Cite this article as: Manju Yadav, Dilip Ramrakhiani, Ajay yadav, Sandeep Nijhawan. Role of Rapid Onsite Evaluation (ROSE) of EUSFNAC in Diagnostic Yield of Solid Mass Lesions. Int J Med Res Prof. 2016; 2(3):163-68 